\title{
A GRANDE EXPLORAÇÃO AGRÁRIA EM PORTUGAL A PARTIR DOS FINS DA IDADE MÉDIA.
}

Portugal, país agrícola, a despeito de tantas dificuldades e limitações impostas pela aridez do solo e inclemências do clima, apresenta, talvez pelos próprios desfavores naturais que o caracterizam, uma longa experiência de organização agrária que se adapta eficazmente às condições produtivas que o seu solo, no geral ingrato, comporta. Essa experiência, caldeada através de tantos séculos de esfôrço de adaptação a um meio difícil, revela-se ao historiador de história agrária, se êste, em vez de se contentar com as formas jurídicas de exploração da terra, se debruçar sôbre a própria técnica de trabalho agrícola, as dimensões da propriedade explorada e o sistema das relações humanas. $\mathrm{Na}$ realidade, conhecidas as técnicas agrárias do nosso país, o seu povoamento - ainda que só aproximadamente - , não podemos considerar como possível uma imagem de produção intensiva do solo em qualquer época da História portuguêsa. A mesma impressão se colhe, se analisarmos os contratos de arrendamento ou outros, não como instrumentos jurídicos, mas no sentido de os relacionar com a realidade econômica. E a própria natureza das relações humanas (onde se não notam lutas sociais nem profundas nem violentas), insinua igualmente um sistema de exploração do solo que precisava dar ao agricultor garantias de usufruição, ao mesmo tempo que as dimensões da unidade agrícola entregue à exploração por contrato, também não dava, reciprocamente, ao rendeiro grandes meios de coação sôbre o dono da terra. E a compreensão do problema melhora consideràvelmente se abandonarmos aquilo a que podemos chamar o grande mito histórico que é a idéia de que a grande propriedade territorial constituiu, até ao século XIX, qualquer espécie de unidade de exploração do solo em Portugal.

As diversas regióes do país, em maior ou menor grau, revelam sempre um predomínio da atividade agrária ao longo 
do tempo. Ainda hoje, e não obstante o grande esfôrço de industrialização levado a cabo neste último meio século, a agricultura constitui o aspecto dominante da economia de Portugal: em 1950 - 46,9\% da população estava ligada profissionalmente à agricultura.

Mas essa longa e remota atividade rural, que marca a vida nacional, não revestil, através do tempo, formas idênticas: de exploração agrária em todo o território português. De fato, os imperativos da Reconquista, emprêsa militar que, para Portugal, se alongou até meados do século XIII e as condições: naturais dêsse território que se tornou português, modelaram a estrutura agrária e social das três regiões fundamentais da terra portuguêsa: Norte atlântico, Norte transmontano e Sul (1).

No Noroeste, onde as serranias e os vales são banhados por chuvas abundantes, domina um clima atlântico que favoreceu, desde bem cêdo, a fixação de densa população e o predomínio da policultura nas terras baixas e nos vales. Assim a pressão demográfica, as condições agrológicas propícias e o clima determinaram um apiroveitamento intensivo do solo, desde os tempos medievais. Região mais cêdo reintegrada na: comunidade cristã peninsular e berço da monarquia portuguêsa, colonizada na sua maior parte pelo esfôrço particular de indivíduos laicos e eclesiásticos, logo foi retalhada entre a nobreza e o clero; nela, as próprias terras da corôa e as dos concelhos eram exíguas, sobrevivendo tenazmente aqui e além, e apesar de tudo, alguns alódios populares.

Desde êsse remoto passado, as unidades agrárias são diminutas e os proprietários rurais abastados possuem muitas pequenas parcelas dispersas. Houve, sempre, diríamos, exploração intensiva mas pequena propriedade, favorecida esta pelos matizes de culturas variadas e rendosas, abastecendo núcleos populacionais relativamente densos e próximos.

Seria nesta área do Noroeste que, a partir da segunda metade do século XVI, o milho grosso (maïs) veio encontrar condições mais favoráveis de expansão, determinando uma ocupação do solo cada vez mais densa e intensa, com a conseqüente tendência, ao fím e ao cabo, para o minifúndio. Só mercê das

(1). - Repartição proposta por Orlando Ribeiro e baseada no contraste entre as influências atlântica e mediterrânea: "A primeira, essencialmente oceânica, contrapõe-se o bloco de regiōes interiores do Nordeste, que as montanhas separam das influências marítimas; o baixo Mondego, a orla do maciço antigo e o sopé da Cordilheira Central, limitam-nas a ambas do resto do país, onde a meridionalidade se traduz pela dominancia progressiva do caráter mediterrâneo. 
transformações expressas na legislação do século XIX, se verificaram certas alterações e casos de reagrupamento de pequenas propriedades (2).

No Nordeste, transmontano e beirão, onde predomina a pobreza do solo e o rigor do clima, a rusticidade da ocupação humana traduziu-se, pelo tempo fora, no aproveitamento de "campos abertos" sujeitos ao afolhamento e à decorrente economia pastoril. Aqui só a grande propriedade ou a cultura extensiva podiam fazer frente às necessidades da agricultura e do pastoreio. Área de colonização difícil, em que se entrelaçavam os vínculos da vizinhança com uma autonomia política e social igualitária dos habitantes, a solução foi em grande parte encontrada na exploração comunitária ou agrupada (3). "A comunidade rural em Trás-os-Montes, que agrupa a exploração dos campos da aldeia, corresponde aos grandes senhores de terras do Alentejo ou do Sueste da Beira, com análogas conseqüências: a exploração em grande baseada no cereal e no rebanho" (Orlando Ribeiro).

Nos territórios ao Sul do rio Mondego, logo com a Reconquista (séculos XII-XIII) surgem os latifúndios. Por necessidade de defesa, de povoamento e arroteio de vastas áreas sem cultura e escassa população, que a guerra assolara e dizimara, fizeram os reis de Portugal largas doações aos mosteiros, às ordens monástico-militares, aos grandes senhores, e até mesmo aos municípios. Talharam-se assim vastes propriedades $e$ agros concelhios, que vincaram indelèvelmente a paisagem agrária do Sul de Portugal. Contudo, essas grandes propriedades, na generalidade e sobretudo ao Sul do Tejo, expandiam-se em terrenos pobres e sob clima sêco e ingrato, e raramente permitiram, até ao século XIX, mais do que uma exploração extensiva, agro-pastoril, determinada pela insuficiência produtiva do solo (4).

Assim, a estrutura agrária do país aparece-nos delineada desde o fim da Idade Média e modelada, quase até nossos dias,

\footnotetext{
(2). - De nossos dias, uma das mais completas e rendosas explorações agrícolıs do Norte de Portugal é constituída por cêrca de 600 hectares de terras, formando um bloco, pertencentes a uma familia e não divididas pelos seus respectivos proprietários, que, pelo contrário, constituiram uma sociedade agrícola familiar para sua exploração direta.

(3). - Nāo obstante a natural divisão da propriedade, a exploraçáo permanecla agrupada no auxílio mútuo dos vizinhos da aldeia.

(4). - No sul de Portugal, em geral, falta água para a vegetação de maio a novembro, e falta calor de novembro a março. No Alto Alentejo, o período produtivo do ano nas áreas não irrigadas resume-se a dois ou trés meses.
} 
por condições e possibilidades naturais, demográficas, econômicas e sociais.

Mas, não obstante faltarem os estudos de pormenor ou de conjunto, parece-nos possível afirmar que, mesmo nas chamadas grandes propriedades - e recordemos que algumas ordens religiosas possuiram terras que totalizavam 40.000 hectares, como o Mosteiro de Alcobaça - , Portugal desconheceu, até meados do século XIX, a grande exploração agrária. E a razão afigura-se-nos residir não só nos condicionalismos já indicados, mas também na forma tradicional como os possuidores da terra foram garantindo o seu cultivo. Isto é, como os proprietários, com pouco capital e escassos recursos técnicos, conseguiram obter, mediantes certas convenções agrárias, uma ocupação efetiva e um cultivo diligente da terra de que lhes. provinham rendimentos e prestaçôes.

De fato, a enfiteuse permitiu ao proprietário territorial, sem alienar, em princípio, o que era seu, fomentar um alarga-. mento econômico-agrário dos seus bens, e propiciou, também, uma "desconcentração" da grande propriedade. Praticada em. relação às terras seculares e eclesiásticas, aos bens da corôa e dos municípios, revestindo, nuns casos ou noutros, forma perpétua ou temporária - podendo ainda os prazos ser hereditários ou de nomeação -, a enfiteuse promoveu o aproveitamento de terras que, sem tal instituto, teriam talvez permanecido. incultas e ermas, ou pelo menos pouco produtivas (5). Numa. palavra, dividiu as áreas territoriais pertencentes aos grandes terra-tenentes em múltiplas unidades de exploração agrária médias ou pequenas, ao mesmo tempo que deu "mobilidade" ao cultivo das terras presas e imobilizadas pelas instituições vinculares.

À enfiteuse recorreu a Ordem de Cristo, o Mosteiro de A1cobaça, a Casa do Infantado, e quantas casas nobres e senhoriais, durante os séculos XV a XIX, não faltando nos seus fundos arquivísticos os numerosos e volumosos livros de registo de. prazos ou aforamentos.

E assim se torna clara e inteligível a posição tomada pela. corôa, na segunda metade do século XVIII, em relação à enfi-. teuse. Quando a realeza procurou quebrar o poder do clero e. da nobreza, que nos foros tinham o seu principal rendimento,

(5). - A finalidade da enfiteuse náo era só promover o arroteamento de terras. virgens; a sua prática serviu também para incrementar a lavoura de campos cerealfferos, de vinhas, de pomares, e, até, de Indústrias anexas: a agricultura (moagem, extraçáo de sal). 
colocou-se ao lado dos foreinos contra os senhorios. Por uma proteção intervencionista de índole econômica e política, que advogava a prevalência da remissão sôbre a devolução, preparou o advento de concepções tendentes a considerar a enfiteuse como um grave obstáculo anteposto ao camponês na aquisição da propriedade plena da terra (Almeida e Costa) .

Todavia, com a sua prática, em parte, se explica, pensamos, a pobreza mas também o equilíbrio do nosso campo, tanto mais que, em muitos casos e no suceder das gerações, se foram atenuando certos gravames, que deixaram de pesar na vida econômica do agricultor e só à sua aguda "sensibilidade" ficou presa a idéia de que "trabalhava em terra alheia" (6).

A importante divisão administrativa de Beja, no centro da principal região produtora de trigo do país e com uma superfície de 114.181 hectares, cujo cadastro acaba de ser publicado, revela-nos que

"o número de propriedades imperfeitas, em que predominam as de enfiteuse, é superior ao das propriedades perfeitas, mas abrange superfície inferior à destas. Apesar de tudo, ainda ocupam cêrca de $28 \%$ da superfície total do concelho" (7).

Outra convenção agrária, mais ou menos contaminada pela enfiteuse e de influência posterior no tempo, o arrendamento, veio reforçar o tipo de pequena ou média exploração agrária que já delineamos. Eram os foreiros e os rendeiros que garantiam, no século XVIII, o cultivo das herdades da Casa de Bragança no têrmo de Olivença e no Alentejo; e, também, dos casais, das quintas e das herdades de um dos maiores proprietários terirtoriais de Portugal, o Duque de Cadaval, em Linda-a-Velha, em Anobra, na Golegã, em Estremoz, em Alcochete, em Olivença, bem como dos Morgados do Maranhão e de Évora e

(6). - O problema da vivificaçāo da enfiteuse ou da sua manutenção, mals ou menos alterada ou adulterađa, ainda é hoje uma realidade viva em Portugal. Tanto assim que êsse instituto figura no anteprojeto de um cos títulos do futuro Código Civil português.

(7). - Quanto ao aproveitamento do solo e à distribuição da propriedade, as conclusões foram as seguintes: "a importância relativa da cultura agri cola diminui à medida que a exploração aumenta de extensáo, sucedendo o inverso com a cultura florestal; apesar de, em todos os tipos de pro. prledade, existir o predomínio absoluto da cultura arvense de sequeiro. é a pequena propriedade que apresenta maior grau de policultura, tra duzido por mais elevadas percentagens de culturas de regadio, de olival, de vinha e de pomar. O grau de policultura diminul a medida que au menta a extensão da propriedade". (Cadastro geométrico da proprtedade rústica. Elementos de informaçáo econômica - Concelho de Beja). 
das Abitureiras. Em 1752, o Duque de Cadaval arrendava por um ano, ao terço e ao quarto, nada menos do que vinte e uma "cortes" (8) nas suas terras de Muge, além de terreno para meloal, para tremoço e para culturas de feijão e de milho grosso (maïs) por determinada porção dos respectivos produtos.

Mas, implicava tal sistema um absenteísmo completo do grande proprietário, ou seja, não faria êle próprio uma lavoura direta e por conta própria? Cremos que a resposta deve ser afirmativa pelo menos em relação ao proprietário nobre e em certas áreas do país.

Seja-nos permitido tomar como exemplo a lavoura do Duque de Cadaval em Muge, no Ribatejo. Isto é, numa região onde não faltam terrenos férteis de aluvião mas onde existem também terrenos ingratos cobertos de sobreirais e pinhais.

Pelo inventário da abegoaria de Muge, sabemos que nela se recolhiam, em 1733, para a utilização na lavoura do Duque, entre outras coisas: 4 carros grandes que serviam de acarretar o pão para a eira; 3 carros pequenos; 4 grades de dentes de pau; 61 cangas de carros e charruas; 12 rodeiros de charruas; 16 dentes de charruas; 12 selinhos de charruas; 18 grades com dentes de ferro; 25 travessas de grades com aprestos de ferro; 4 grades boieiras com dentes de ferro; 7 aivecas de charruas com fivelas de ferro; 4 forcados grandes e 5 pequenos de ferro; 17 forquilhas de ferro; 4 machados; 29 enxadas; 23 sachos; 3 foices rossadouras e 2 foices de ceifar; 5 rêdes e 6 panais de acarretar palha.

No mesmo ano, e na adega, existiam: 15 tonéis; 4 botas (9); 10 "butes" grandes de Holanda; 22 pipas; 4 dornas grandes; 2 celhas grandes e 2 pequenas; e 2 funis de pau.

Esta simples enumeração indica, de igual forma, uma exploração agrária a que não podemos chamar grandes.

Se perscrutarmos, agora. o aproveitamento da zona florestal, deparam-se-nos ainda alguns arrendamentos para pascigo, sem excluir, de modo algum, a sua utilização, parcial ou total, em certos pontos, pelos gados do proprietário ou por êle reservada para caçar (10)

Sem sairmos do mesmo ano de 1733, em Muge, o gado existente dividia-se assim: 210 cavalos e éguas de trabalho, de sela

(8): - Têrmo usado para designar certa extensão de terreno lavrado rodeado de valas.

(9). - Espécie de tonel mas de menor capacidade.

(10). - Além da caruma, foram tiradas do pinhal de Escaroupim, em 1743, 2967 carradas de achas e 203 carradas de faxina. Nos sobreirais, o rendimento provinha ainđa da extração da cortiça e dos cortes de madeira para fazer carvão "de sobro". 
e de tiro; 279 bois e vacas de raças diversas; 41 vacas holandesas; 175 touros e vacas bravas; 676 ovelhas; 306 cabras; e 493 porcos.

De tudo quanto acabamos de referir, legítimo se torna aceitar a hipótese que formulamos de que os grandes proprietários territoriais portuguêses, laicos ou eclesiásticos, e também os soberanos, não promoveram grandes explorações agrárias, mas possuiram sim, e curioso é sublinhá-lo, grandes administrações onde se concentrava a contabilidade e o recebimento dos foros e das rendas que cobravam das suas terras, e donde partia a distribuição e colocação dos seus rendimentos em gêneros e em dinheiro (11) .

Porém, chegado o século XIX um vento agreste e nôvo, aliás já pressentido desde o último quartel do século XVIII, soprou sôbre a tradicional exploração agrária portuguêsa, tanto pelo que respeitava ao aproveitamento do solo como à distribuição da propriedade. A extinção das ordens religiosas, por decreto de 28 de maio de 1834 , e a liquidação e venda em hasta pública dos seus bens, veio lançar no mercado vastas áreas territoriais e abriu caminho rápido a "novos" proprietários nãolavradores. Dispondo de capitais, quase sempre amealhados noutras profissões e atividades, no comércio, na indústria, ou na banca, alguns dos recém-chegados à posse da terra acumularam quantas propriedades puderam e abalaram a estrutura portuguêsa. Também não foram raros os casos em que os antigos ou grandes proprietários, mercê de disponibilidades várias, arredondaram o seu patrimônio territorial adquirindo mais terras e herdades (12).

Por outro lado, as lutas civis entre legitimistas e liberais (1828-1834) e a subseqüente vitória dêstes últimos, pondo em prática as idéias teóricas e doutrinais dos economistas oficiais, bem como a abolição dos morgados (por diplomas de 4 de abril de 1832 e 19 de maio de 1863), que deu livre curso ao ritmo das

(11). - No estudo que temos em preparaçāo sôbre a Casa de Cadaval e as suas propriedades, assim como uma biografia do $1 .^{\circ}$ Duque, $D$. Nuno Alvares Pereira de Melo, se examinará mais detidamente êste ponto.

(12) . - Uma das grandes propriedades do Alto Alentejo constituindo um só prédio com 1.770 hectares, entre Alter Pedroso e Portalegre, pelo seu nome de Chancelaria e pelas cruzes que ostentam os marcos que a dilimitam, denota bem ter sido outrora pertença da Ordem de Avis. Esta propriedade foi dividida em 1958 por motivo de partilhas. 
divisões sucessórias, favoreceram a aquisição de terras e de propriedades, e, até, a reconstituição de grandes herdades (13).

Reduzindo-se, ainda, velhos comunitarismos agrários, fragmentando-se, vendendo-se ou aforando-se baldios comunais (14), mais se acelerou durante o século XIX a divisão da propriedade, mas também, e paradoxalmente, se tornou possível o aparecimento de grandes explorações unitárias no Centro e no Sul do país (15) .

Desta situação confusa e anômala foi emergindo, a pouco e pouco, uma nova exploração agrária portuguêsa, a partir do terceiro quartel dêsse século, graças a elementos diversos que, em parte, alteraram o seu arcaico condicionalismo. A avassaladora expansão da cultura do milho em regime de sequeiro e da batata a tôdas as regiões de Portugal permitiu, conjuntamente com a da vinha e das culturas hortenses, a subsistência vivaz e até o incremento da pequena exploração agrária. Com a abertura de estradas e a construção de caminhos de ferro, fomentou-se a circulação e colocação dos produtos que passaram a transcender o consumo local, o que aproveitou a grandes e a pequenos.

A generalização do adubo químico e das técnicas modernas, os aproveitamentos de águas para irrigação, onde e quando era possível fazê-lo, e a legislação protetora à cultura cerealífera (16), determinaram um arroteamento de terras virgens e uma intensificação da exploração agrícola em todo o país, mas mais acentuadamente nas regiões ao Sul do rio Mondego.

E' suficiente dizer, para fundamentar tal intensificação, que, sendo a superfície total de Portugal de 8.906 .000 hectares, em 1874 sòmente 4.598 .500 hectares eram cultivados, enquanto a área cultivada em 1957 foi de 6.630 .000 hectares (17).

(13). - Para compra e aproveitamento de terras que haviam pertencido à Casa do Infantado, constitui-se em 1836 uma companhia por açōes, a Companhia das Lezírias do Tejo e Sado. Só a área adquirida pela Companhia na lezíria de Vila Franca de Xira andava por volta de 10.000 hectares.

(14). - Quando se procedeu ao reconhecimento dos baldios ao Norte do rio Tejo para a elaboração do "Plano de Povoamento Florestal", de 1940, verificou-se que êles cobriam ainda 512.308 hectares.

(15). - Como a Casa de Cadaval, que adquiriu durante o século XIX terras e bal dios comunais em Muge. Ainda não há cinco anos, tôdas as propriedades situadas no Ribatejo, e subordinadas a administração dessa casa senhorial de Muge, totalizavam cêrca de 13.000 hectares. Partilhas sucessórias vieram subseqüentemente interferir na sua orgânica administrativa e di vidir propriedades entre vários herdeiros.

(16). - A primeira lei é de 1 de julho de 1889, a chamada lel dos cereais.

(17). - A estatística agrícola de 1957 considerou 668.000 hectares insuscetivels de cultivo. 
Analisando as culturas e o revestimento florestal mais representativos:

\begin{tabular}{|c|c|c|c|}
\hline & 1874 & 1957 & \\
\hline Trigo $\ldots \ldots \ldots$ & 260.000 ha. & 814.000 & ha. \\
\hline Milho $\ldots . . . \ldots$ & $520.000 "$ & 483.000 & $"$ \\
\hline Arroz $\ldots \ldots \ldots$ & 7.000 & 37.000 & $"$ \\
\hline Vinha $\ldots \ldots \ldots$ & 204.000 & 380.000 & $"$ \\
\hline $\begin{array}{l}\text { Olival } \ldots \ldots \ldots \\
\text { Montados (sobro }\end{array}$ & 200.000 & 420.000 & r \\
\hline e azinho) & $370.000 "$ & 1.000 .000 & $"(18)$ \\
\hline Pinhal ......... & $210.000 "$ & 1.170 .000 & $"$ \\
\hline
\end{tabular}

De então, e de época posterior, datam as grandes explorações agrárias portuguêsas, às quais, em certas áreas irrigadas, não foi indiferente a difusão da cultura do arroz.

Contudo, nestes últimos anos, tem-se verificado em Portugal uma progressiva divisão e fragmentação da propriedade (19) . O ritmo dessa divisão em 1952 era de 50.000 prédios rústicos por ano, num total de 11.308 .846 prédios (Rui de Andrade) (20) e num país com uma superfície de 8.906 .000 hectares dos quais, em 1957, 6.630 .000 sujeitos a exploração. Curioso é salientar que uma determinação legal, publicada em 1926, proibiu a divisão de propriedades com área inferior a 1 hectare.

\section{Considerando que Portugal}

"é um campo só de milho e trigo, com uma parte úmida e a outra árida, e atrás a vinha, e a oliveira e o sobreiro e no último plano, já a trepar pela encosta, o pinhal bastio - teremos neste quadro, aproximadamente, tôda a figura da agricultura portuguêsa e a indicação de todos os seus problemas culturais" (Pequito Rebelo).

(18). - Dos quais 600.000 hectares de sobreiros e 400.000 de azinheiras.

(19). - Com a devida ressalva de algumas exceçōes, como o caso de Barreira \& Companhia (Irmãos) que, de negociantes de cortiça, se tornaram grandes proprietários e produtores de cortiça.

(20). - Neste cálculo devemos ter em consideração: 1.0 - que uma proprledade pertencente ao mesmo indivíduo pode ser formada por vários prédios rús tícos; 2.0 - que muitas vêzes as grandes unidades de exploração nío correspondem a unidades de propriedade, por pertencerem as terras que a constituem a vários membros de uma mesma familla. 
Assim é hoje, mas êste fato não nos deve fazer esquecer quão profícuo será estudar o caminho jurídico e técnico já percorrido e relacioná-lo com os problemas contemporâneos.

Para quem estuda a história econômica brasileira, estas considerações não serão certamente desprovidas de interêsse, porquanto foi à luz desta experiência que floresceu a atividade agrícola do Brasil colonial. Assim como também é certo, creio, que, a despeito das aparências, não é a grande unidade de exploração agrária que domina, ou de qualquer modo caracteriza a história brasileira até ao século XIX. 